\title{
INDISCIPLINA E VIOLÊNCIA NA ESCOLA: FATORES QUE INTERFEREM NA PRÁTICA PEDAGÓGICA DE PROFESSORES DE UMA ESCOLA PÚBLICA DE CARUARU
}

\author{
Natalia Lima Tavares das Chagas ${ }^{1}$ \\ Eliete Francisca da Silva Farias ${ }^{2}$ \\ Marcela Tarciana Cunha Silva Martins ${ }^{3}$
}

RESUMO: A violência escolar, por vezes, é considerada equivocamente como um ato de indisciplina e pode ocorrer de maneira silenciosa, e despercebida pelos professores. Esta preocupação tem exigido um olhar mais cuidadoso por parte dos profissionais de educação. A partir deste contexto o presente estudo teve como principal objetivo analisar como a indisciplina e a violência podem interferir na prática pedagógica em duas escolas pública. A metodologia utilizada foi uma pesquisa de campo, descritiva e de abordagem qualitativa em duas escolas do município de Caruaru-PE. Os sujeitos da pesquisa foram io professores da Escola Municipal Caic Dr. Amaro Lyra e Silva e ro professores da Escola Municipal Cesarina Moura Vieira Costa, totalizado 20 participantes, que atuam em sala de Ensino Fundamental I e II. O instrumento de coleta de dados utilizado foi o questionário e os dados obtidos foram analisados na perspectiva qualitativa. Os resultados sugerem um ambiente escolar com muitos casos de indisciplina o que se torna pouco atrativo e inapropriado às aulas, o que acentua as faltas dos alunos podendo levar a repetência ou até mesmo a evasão escolar, como também a exclusão da escola, além de interferir na qualidade do ensino. Tais acontecimentos trazem consequências drásticas tanto para o agredido como para o agressor que é prejudicado em seu desenvolvimento escolar. $\mathrm{O}$ professor deve estar atento e preparado para lidar com a situação, visto que são profissionais peças-chave para que os projetos de prevenção da violência escolar deem certo. A formação deve ser permanente, assim como as ações para diminuição das violências, do estresse e do esgotamento que afetam a todos.

Palavras-chave: Ambiente escolar. Agressão. Formação.

ABSTRACT: School violence is sometimes mistakenly regarded as an act of indiscipline and can occur silently and unnoticed by teachers. This concern has required a more careful

\footnotetext{
Mestre em Ciências da Educação pela Veni Creator Christian University. E-mail: nataliachagas_2013@hotmail.com.

${ }^{2}$ Doutoranda em Ciências da Educação pela Veni Creator Christian University. E-mail: franliethe@hotmail.com.

3 Doutora em Agronomia pela Universidade Federal da Paraíba. Professora do Curso de Mestrado e Doutorado em Ciências da Educação pela Veni Creator Christian University. E-mail: marcela.tarciana@yahoo.com.br
} 
look on the part of education professionals. From this context, the present study had as main objective to analyze how indiscipline and violence can interfere in the pedagogical practice in two public schools. The methodology used was a field research, descriptive and qualitative and quantitative approach in two schools in the city of Caruaru-PE. The research subjects were io teachers from the Municipal School Caic Dr. Amaro Lyra e Silva and Io teachers from the Municipal School Cesarina Moura Vieira Costa, totaling 20 participants, who work in Elementary Schools I and II. The data collection instrument used was the semi-structured questionnaire and the data obtained were analyzed from a qualitative perspective. The results suggest a school environment with many cases of indiscipline, which becomes unattractive and inappropriate to classes, which accentuates student absences, which can lead to repetition or even dropout, as well as exclusion from school, in addition to interfering in the quality of teaching. Such events bring drastic consequences for both the victim and the aggressor who is harmed in their school development. The teacher must be attentive and prepared to deal with the situation. Since they are professionals who are key parts for projects to prevent school violence to work. Training must be permanent, as well as actions to reduce violence, stress and exhaustion that affect everyone.

Keywords: School environment. Aggression. Formation.

\section{INTRODUÇÃO}

O homem em seu estado irascível emprega ilegitimamente da força bruta para coagir seus oprimidos e assim, dominá-los e impor suas vontades próprias. A violência tornou-se tão trivial que foi usada habitualmente por séculos e séculos como forma de educar crianças, domesticar mulheres, punir escravos, domar animais, reivindicar direitos, impor regras e demais atos em que a violência em uma atitude sensata não seria necessária (ARENDT, 2004).

Infelizmente, ainda se pode ser testemunha ou vítima de tais atos, o diferencial é que atualmente conta-se com leis mais severas que protegem crianças, mulheres, negros, homossexuais e idosos de maus-tratos, legislação necessária visto que o mundo vive em guerra, seja a guerra urbana, civil ou religiosa. Há décadas pessoas morrem a cada minuto por causa da crescente violência (TUROLLO JR, 2015).

São assustadores os índices de crescimento da violência mundial e o Brasil se destaca com níveis acima da média em relação à violência armada e homicídios. O Mapa da Violência 2019, divulgado Instituto de Pesquisa Econômica Aplicada (IPEA) mostra que mais de 65 mil brasileiros foram mortos por armas de fogo no Brasil em 2017, com aumento no Norte e no Nordeste. Segundo o instituto um índice considerável e aceitável é de io homicídios para cada roo mil habitantes (IPEA, 2019).

Diante desse quadro é possível listar alguns dos principais fatores que geram e contribuem para o aumento da violência mundial, em especial no Brasil: a impunidade, o desemprego, a educação de baixa qualidade, a desestruturação familiar, o tráfico de drogas, 
a falta de segurança, a má distribuição de renda, resultados da urbanização descontrolada, o paradoxo entre o convívio com a riqueza e a pobreza, a segregação social e aumento da população nos grandes centros urbanos. Porém, é imprescindível ressaltar que a falta de humanidade, de tolerância e de respeito devem ser levados em consideração como motivos desencadeadores de atividades nefastas que tornam o mundo cada dia mais hostil e perverso (TUROLLO JR, 2015).

No ambiente escolar, as agressões contra professores e alunos são comuns em grande parte das escolas e universidades de todo mundo, independente da classe social que esteja inserida. Uma pesquisa global realizada com mais de cem mil professores e diretores pela Organização para a Cooperação e Desenvolvimento Econômico (OCDE) põe o Brasil no topo das agressões contra professores. Segundo a pesquisa 12,5\% dos professores brasileiros entrevistados relataram serem vítimas de agressões verbais ou físicas no exercício de sua função pelos seus alunos. Esse índice foi considerado alto entre os trinta e quatro países entrevistados, visto que, a média entre eles foi de 3,4\%. Países como a Malásia, Coréia do Sul e Romênia o índice é zero (FERNANDES, 2014).

Para entender melhor a violência escolar torna-se necessário recorrer a aspectos referentes ao exterior e interior da instituição, e o comportamento das vítimas e dos agressores por onde circulam. Entre os aspectos externos, é preciso levar em conta, as ideias de Santos (2017, p. 6), quando ressalta que "questões de gênero, relações raciais, situações familiares, influência dos meios de comunicação, espaço social das escolas" são fatores frequentes e geradores desses atos.

\section{Referencial Teórico}

Antes de analisar o tema da violência na comunidade escolar brasileira é importante lembrar, mesmo que de maneira parcial um pouco da definição de violência. É muito complexo definir a violência, notadamente por ser ela, muitas vezes, uma maneira própria de relação pessoal, política, social e cultural; em outras vezes resulta das interações sociais; ou ainda se trata um elemento cultural natural daquela sociedade (BERRINGER, 2017).

Vários estudos e estudiosos do assunto nos últimos tempos têm apresentado diversas interpretações, em diferentes contextos. Inicialmente associa a violência à agressividade relativa ao instinto natural do ser humano, o que o impulsiona a matar e a levar o seu semelhante a sofrer. Num segundo momento a define como resultado de conflitos de interesse, sendo, assim, um princípio geral da ação humana diante de situações competitivas. Numa terceira disposição, progride para a ideia de construção de "identidade de interesses" (BERRINGER, 2017).

Em relação à violência escolar, o ponto de partida para a reflexão mais ampla sobre o tema deve ser o próprio conceito neste ambiente que de acordo com Elias (2011, p. II) a violência:

Envolve qualquer tipo de violência que ocorra no contexto escolar, com qualquer pessoa ou instituição que tenha vínculo direto ou indireto com a escola. Desse contexto é preciso destacar vários aspectos importantes. O primeiro refere-se à enorme variedade ou diversidade de violências que vão requerer ações diferentes. 
[...] O segundo aspecto se refere ao âmbito. Pode ocorrer, então, nos diversos espaços dentro dos muros da escola - incluindo salas de aula, banheiros, corredores, pátios etc. - [...] e ainda em atividades extraescolares ou não diretamente educativas, no jogo de futebol, no ensaio de música. [...] O terceiro aspecto importante diz respeito às pessoas, na condição de agentes ou de vítimas da violência escolar.

Já em se tratando de indisciplina de acordo com Estrela (2012, p 19) "está relacionado com a existência de regras; e o conceito de indisciplina, com a desobediência a essas regras". Queiroz (2015, p.9) complementa que:

\begin{abstract}
A indisciplina e todos os fatores ligados ao comportamento do aluno, como desrespeito, xingamentos, depredação e até agressão física são agentes causadores da violência escolar. Desobediência às normas da escola como deixar de usar o uniforme, sair da sala de aula sem autorização, não realização de atividades, não levar os materiais escolares e etc.
\end{abstract}

No entanto, nem sempre o cumprimento de normas e regras é a realidade vivida pelas escolas. Mas é essencial e deve estar relacionada aos objetos maiores da comunidade escolar e principalmente ao objetivo de auxiliar na formação de alunos críticos e participativos na sociedade a qual está inserida.

A sociedade em si passa por grandes transformações; vive-se na era da informação, e, ao mesmo tempo com tanto conhecimento, não se pode resolver os problemas do cotidiano como num passe de mágica. O que se percebe é um atribuindo a causa do problema ao outro. Se a violência é um fenômeno social e todos são inseridos na sociedade, então, este problema é de todos. De nada adianta identificar o problema, se não houver a busca de uma solução. É preciso tomar esse desafio como compromisso e missão para que assim possa construir uma sociedade mais justa e igualitária, na qual o cidadão tenha os mesmos direitos e deveres onde ninguém seja discriminado, humilhado e maltratado (FERNANDES, 2014).

Diante deste contexto de violência e indisciplina a escola tem uma função relevante na solução dessa problemática, visto que este comportamento agressivo tem causado grandes problemas de ordem emocional apontado como um dos fatores que interferem na prática pedagógica e responsável pelas dificuldades de aprendizagem, que é, sem dúvida, um dos mais graves problemas com o qual a realidade educacional brasileira vem convivendo há muitos anos e que tal ocorrência se evidencia praticamente em todos os níveis de ensino do país (QUEIROZ, 2015).

De acordo com Elias (20II) por se tratar de um ambiente voltado para as necessidades educacionais e sociais dos alunos, cabe aos profissionais, que ali atuam, analisar a participação dos pais no contexto escolar do filho, o comportamento e a interação entre os colegas na escola, uma vez que se tem verificado um número muito grande de problemas de indisciplina e violência no ambiente escolar que tem interferido na prática pedagógica. 


\section{Marco Metodológico}

O estudo caracteriza-se como uma pesquisa de campo, de natureza descritiva, de abordagem qualitativa. O campo da pesquisa foram duas (2) escolas da rede municipal de ensino: Escola Caic Dr. Amaro de Lyra e Silva (Escola A) e Escola Municipal Cesarina Moura (Escola B), localizadas no município de Caruaru, estado de Pernambuco, Brasil. Os sujeitos pesquisados foram vinte (20) professores, sendo dez (Io) da Escola A e dez (Io) da Escola B do quadro geral de professores que atuam no Ensino Fundamental I e II.

$O$ instrumento utilizado para a coleta dos dados foi o questionário e a partir dos dados coletados, procedeu-se a análise de cada questão. E para preservar a identidade dos participantes foi atribuída a sigla PA para professores da Escola A e PB para os professores da Escola B, levando em consideração o numeral correspondente a cada professor das escolas mencionadas anteriormente.

\section{Resultados e Discussão}

A partir de uma descrição analítica buscou-se realizar uma análise qualitativa, através do questionário, aplicado contemplando o trabalho do docente em torno da violência e indisciplina no ambiente escolar, constituindo-se numa preocupação que está diretamente ligada com questões que envolvem a complexidade dos órgãos governamentais das instituições de ensino, especificamente na Rede Municipal de Caruaru/PE.

Diante do quadro atual do ensino com a violência escolar no Brasil foi questionado como profissional qual seria a ideia em relação à violência na escola onde leciona, ou seja, os tipos de manifestações de violência e indisciplina. Os participantes se posicionaram conforme apresenta o Quadro I.

Quadro I: Os tipos de manifestações de violência entre os alunos da Escola Municipal Caic Dr. Amaro Lyra e Silva e Escola Municipal Cesarina Moura do município de Caruaru-PE.

\begin{tabular}{|c|l|}
\hline $\begin{array}{c}\text { Identificação } \\
\text { do profissional }\end{array}$ & \multicolumn{1}{|c|}{ FD: Tipos de manifestações de violência da na escola } \\
\hline PAı & Perturbação da paz, humilhação, violência física e psicológica. \\
\hline PA2 & $\begin{array}{l}\text { Verbal (falar mal, empurrar) - física e material (bater, roubar, empurrar) } \\
\text { psicológica e moral (excluir, difamar). }\end{array}$ \\
\hline PA3 & $\begin{array}{l}\text { No ambiente escolar as formas de manifestações de bullying são por causa de } \\
\text { classe social, aparência física entre outras. }\end{array}$ \\
\hline PA4 & $\begin{array}{l}\text { Se manifesta mediante uma grande diversidade, tais como: falar mal, ameaçar, } \\
\text { empurrar, bater, ignorar, etc. }\end{array}$ \\
\hline PA5 & Agressão verbal, agressão física. \\
\hline PA6 & Brincadeiras desagradáveis, apelidos, exclusão, agressões físicas, etc.. \\
\hline
\end{tabular}




\begin{tabular}{|c|c|}
\hline $\mathrm{PA}_{7}$ & $\begin{array}{l}\text { Maus tratos entre colegas de escola, repetidas vezes durante o ano letivo contra } \\
\text { uma mesma vítima. }\end{array}$ \\
\hline PA8 & Agressão física e verbal com o intuito de humilhar a vítima. \\
\hline $\mathrm{PA}_{9}$ & Piadinhas, brincadeiras sem graça e menosprezar o colega. \\
\hline PAio & $\begin{array}{l}\text { Excluir, perseguir, agredir verbalmente e fisicamente, ameaçar e entre outras que } \\
\text { muitas vezes passam despercebidas dos professores. }\end{array}$ \\
\hline PBII & $\begin{array}{l}\text { Se manifesta por grande diversidade de comportamento agressivos tais como: } \\
\text { insultar, ignorar, bater, empurrar, ameaçar, falar mal, etc.; }\end{array}$ \\
\hline $\mathrm{PB} 12$ & $\begin{array}{l}\text { Alguns alunos são alvos de bullying na maioria das vezes por causa da aparência } \\
\text { física. }\end{array}$ \\
\hline $\mathrm{PB}_{13}$ & $\begin{array}{l}\text { Apelidos pejorativos, agressões físicas ou verbais em relação à magreza, beleza, } \\
\text { obesidade, etc. }\end{array}$ \\
\hline $\mathrm{PBi}_{4}$ & $\begin{array}{l}\text { Verbal - insultos, ofensas, apelidos pejorativos; física e material - bater, } \\
\text { empurrar, roubar. }\end{array}$ \\
\hline PBi5 & $\begin{array}{l}\text { Psicológico, apelidos pejorativos, verbal, tirar dinheiro ou lanche, ameaçar, falar } \\
\text { mal, etc. }\end{array}$ \\
\hline PBi6 & $\begin{array}{l}\text { As mais comuns são: preconceito racial, religioso, físico e intelectual ou } \\
\text { deformação genética. }\end{array}$ \\
\hline $\mathrm{PBI}_{7}$ & Brincadeiras que humilham. Xingamentos, provocações e agressões físicas. \\
\hline $\mathrm{PBI} 8$ & $\begin{array}{l}\text { As manifestações são por meios de agressões verbais, quando os alunos usam de } \\
\text { chateações com palavras pejorativas para humilhar os demais. }\end{array}$ \\
\hline PBig & $\begin{array}{l}\text { Nas formas de brincadeiras que consistem em colocar apelidos, excluir, ofender, } \\
\text { agredir verbalmente e fisicamente, humilhar e tantos outros atos para constranger } \\
\text { a criança. }\end{array}$ \\
\hline $\mathrm{PB}_{20}$ & $\begin{array}{l}\text { O mesmo apresenta dificuldade de inclusão para com os alunos ou é vítima de } \\
\text { brincadeiras de mau gosto. Ou seja, sentem a rejeiçâa dos colegas "professores" } \\
\text { com outro, ou seja, a falta de relaçâa interpessoal com os colegas. }\end{array}$ \\
\hline
\end{tabular}

Fonte: Dados da pesquisa de campo (2021)

Todos os professores apresentaram um comportamento distinto de alunos que praticam atos de violência muitas vezes caracterizados como indisciplina ou bullying com o colega em sala de aula e os professores PAr, PA3 da Escola $\mathrm{A}_{3}$ e PB2o e PBi9 da Escola B, são representados pela fala do professor PBi6 da Escola $B$ que resumiu as diversas formas de atingir outras pessoas e que tem um pouco de cada, ou seja, "preconceito racial, religioso, físico e intelectual ou deformação genética". É comum verificar no ambiente escolar aquele aluno que deliberadamente procura maltratar o outro no seu ponto mais fraco, ou por achar que seja, no momento que é agredido, por ser um alvo fácil o comportamento do agressor torna-se repetitivo. A maioria das agressões são justamente por questões que envolvem cor da pele, meninas que muitas vezes não participam de alguma brincadeira por ser evangélica, por ter alguma deficiência física etc. 
Para Abramovay e Rua (2012, p. 4I) a escola com a finalidade de contribuir para a "construção de uma cultura contra violências, faz sentido lidar com discriminações, intolerâncias e exclusões no espaço escolar, ainda que essas não deságuem em ameaças, brigas e mortes, ou seja, não se consubstanciando em violência física propriamente dita”.

São questões conflitantes que são vivenciadas diariamente e na mesma proporção são debatidas e combatidas. De acordo com Elias (1994, p. 23): a agitação e "o medo provocados por esses conflitos em todas as pessoas implicadas podem ser vistos na carga efetiva de que se revestem todas as palavras direta ou indiretamente relacionadas com eles".

Nas escolas estudadas os problemas com os vários tipos de preconceitos apresentados pelo professor PBi6 da Escola B são constantes, necessitando de uma vigilância permanente para que esses tipos de comportamentos não se repitam e gerem constrangimento ao aluno.

Os professores também se posicionaram afirmando em conversa informal que muitos alunos começam a apresentar atitudes violentas quando são agredidos verbal ou fisicamente por outro colega; em brincadeiras desagradáveis; quando são apelidados; se criticam seus familiares ou locais onde residem de maneira pejorativa; são ironizados pelo modo como se vestem ou se portam; pela cor da pele; opção sexual; etc. Os professores em seus relatos destacaram que a violência, principalmente o desrespeito, é uma constante no meio escolar.

Por ser a escola um ambiente social em que os jovens estão começando a conhecer e a experimentar as diversas situações, precisa também ir aprendendo a conviver com as diferenças, cabendo aos educadores mostrar o caminho certo sobre as questões essenciais para se viver em sociedade.

De acordo com Fante (2015) a violência não se refere "apenas quanto à sua manifestação física, mas também quanto às situações de humilhação, exclusão, ameaças, desrespeito, indiferença, omissão para com o outro". Que se for um tratamento dispensado com frequência ao mesmo indivíduo torna-se um ato de bullying.

Os professores PA8, PA9, da Escola A e PBir, PBi5, PBi8, PBi9 da Escola B são representados pelo pensamento do professor $\mathrm{PB}_{17}$ da Escola $\mathrm{B}$ que independente do tipo de comportamento todos eles são "brincadeiras que humilham". Dependendo das características individuais de cada vítima a humilhação vivenciada pode deixar traumas para o resta da vida. Percebe-se pelos posicionamentos dos professores, e só vem a confirmar as consequências que a humilhação que os alunos sentem devido a esses atos de violência e bullying geram efeitos negativos, tanto no ambiente escolar com o baixo rendimento nas atividades, deficiência de concentração, pouca interação com os demais colegas, como fora do período escolar, ao gerar o desinteresse em ir pela escola podendo levar a evasão.

É importante que criança e o adolescente tenham uma vida saudável, sem comportamentos que possam prejudicar o seu desenvolvimento e que tragam consequências para a sua vida adulta. Como também é necessário ter um olhar cuidadoso ao comportamento apresentado pelo aluno, ele pode dizer muito ao professor para que 
possa mediar o conflito que tanto pode prejudicar o agressor como o agredido no ambiente escolar. Para os professores participantes da pesquisa de acordo com as características da violência, percebe-se que nas escolas estudadas são comportamentos que frequentes (MELO, 2010).

Os participantes das escolas A e B estudadas acrescentaram que existem alguns alunos que já são vistos com uma característica específica em decorrência de ser constantemente chamado de baleia fora d'água, quatro olho, dumbo, Olívia palito, ET, tamburete, manequim da Brasilgás, mesmo tendo o professor feito diversas observações para que este tipo de comportamento não se repita, basta apenas que não esteja por perto para o agressor volte a agir da mesma forma. Esses apelidos geralmente causa vergonha ao agredido por ser dito na maioria das vezes na frente de outras pessoas, o que vem a reforçar as considerações dos professores PA8, PA9, da Escola A e PBII, PBi5, PBi7, PBi8 e PBi9 da Escola B na questão anterior constante no Quadro I que esse tipo de brincadeira causa humilhação e podem gerar tristeza e desinteresse pelos estudos.

$\mathrm{O}$ professor $\mathrm{PB}_{20}$ da Escola $\mathrm{B}$, também faz referência a uma questão muito importante e que deve ser devidamente trabalhada e muitas vezes podem ser a principal chave para reduzir o comportamento de violência e indisciplina na escola que é relação interpessoal entre todos que fazem o ambiente escolar.

Essa relação professor e aluno é muito importante para que não haja empatia tanto em relação a disciplina, a escola e aos amigos de turma, visto que terá no professor o exemplo da importância de ter um bom relacionamento com o outro. Oferece segurança, por parecer ser próximo a uma figura familiar, sensível as necessidades dos alunos, principalmente em relação indisciplina, não deve discriminar para dar o exemplo de comportamento social e de relação. É necessário que o próprio educador compreenda que a sua tarefa enquanto agente facilitador no processo ensino-aprendizagem é entender que tal tarefa exige preparo especializado, não apenas do conteúdo curricular, e o seu grande desafio é conhecer e compreender o modo dos alunos serem e estarem no mundo e quanto maior esse conhecimento, maiores serão as possibilidades de transformação tanto pessoal como social (ABRAMOVAY; RUA, 2012).

Trabalhar adequadamente as relações interpessoais no ambiente escolar pode contribuir para que não haja problemas emocionais que muitas vezes são determinantes para alterações comportamentais, tanto na relação professor/aluno como aluno/aluno, isto porque o professor quando se relaciona com o aluno lhe transmite muitas mensagens de várias maneiras, dizendo sempre alguma coisa que faça com que eles se relacionem e se comuniquem entre si, sobretudo quando há uma estrutura e um senso de direção nas situações de relação que se procura oferecer aos alunos (MORALES, 2008).

Independente de ser um ato de violência ou uma violência velada como no caso do bullying, ou mesmo indisciplina, todos são comportamentos destrutivos, que em nada contribui para o desenvolvimento do processo de ensino-aprendizagem e crescimento pessoal e social do aluno. 
$\mathrm{Na}$ sequência foi solicitada uma descrição do desenvolvimento do processo de ensino-aprendizagem nas escolas, ou seja, as consequências dos atos de violência e indisciplina mais comuns entre os alunos.

Quadro 2. As consequências em decorrência dos atos de violência e indisciplina entre os alunos da Escola Municipal Caic Dr. Amaro Lyra e Silva e Escola Municipal Cesarina Moura do município de Caruaru-PE.

\begin{tabular}{|c|c|}
\hline \multicolumn{2}{|r|}{ FD: Consequência dos atos de violência e indisciplina na escola } \\
\hline $\begin{array}{l}\text { Identificação } \\
\text { do profissional }\end{array}$ & Excerto de Depoimentos (ED) \\
\hline PAI & $\begin{array}{l}\text { Baixo rendimento escolar, evasão, timidez, solidão, constrangimento e até mesmo } \\
\text { suicídio. }\end{array}$ \\
\hline PA2 & $\begin{array}{l}\text { As consequências referentes aos atos de violência são inúmeras e variadas, elas } \\
\text { afetam as vítimas, agressores e as testemunhas prejudicando-os na formação } \\
\text { "psicológica, emocional e sócio educacional”. }\end{array}$ \\
\hline $\mathrm{PA}_{3}$ & $\begin{array}{l}\text { Podem trazer consequências para o aluno envolvido em todos os sentidos. Tanto } \\
\text { emocional, físico, psicológico e sócio educacional. }\end{array}$ \\
\hline $\mathrm{PA}_{4}$ & $\begin{array}{l}\text { Não querer mais frequentar as aulas, pedir para mudar de turma ou escola, queda } \\
\text { no rendimento escolar, dificuldade de atenção. }\end{array}$ \\
\hline PA5 & Trauma para toda a vida e sequelas psicológicas. \\
\hline PA6 & Desinteresse, depressão, baixo rendimento, problemas psicológicos, traumas, etc. \\
\hline $\mathrm{PA}_{7}$ & $\begin{array}{l}\text { Em alguns casos extremos as consequências podem ser trágicas, pois o aluno } \\
\text { poderá cair em profunda depressão, levando-o ao suicídio. }\end{array}$ \\
\hline PA8 & Depressão, isolamento, agressividade e algumas vezes tendência a suicídio. \\
\hline PA9 & Impossibilidade de inclusão no qual o mesmo se sente inferior aos outros colegas. \\
\hline PAio & $\begin{array}{l}\text { Várias consequências como: baixo rendimento escolar, evasão, ansiedade, } \\
\text { agressividade, alterações psicológicas. }\end{array}$ \\
\hline PBII & $\begin{array}{l}\text { Isolamento, baixo autoestima, falta de vontade de ir a escola, e rejeição a mesma, } \\
\text { ansiedade, dificuldade de relacionamento e mudanças de humor. }\end{array}$ \\
\hline $\mathrm{PB}_{12}$ & $\begin{array}{l}\text { As consequências são gravíssimas as pessoas ficam isoladas e muitas chegam a } \\
\text { cometer suicídio. }\end{array}$ \\
\hline $\mathrm{PB}_{13}$ & $\begin{array}{l}\text { Ansiedade, falta de vontade de ir a escola e rejeição da mesma, dificuldade de } \\
\text { concentraçâa, etc. }\end{array}$ \\
\hline $\mathrm{PB}_{14}$ & Eles têm vergonha de retornar à escola, apresenta baixo rendimento, não interage. \\
\hline PBis & $\begin{array}{l}\text { Desenvolvem-se práticas que acabam prejudicando o aluno no seu desempenho em } \\
\text { sala. }\end{array}$ \\
\hline PBi6 & $\begin{array}{l}\text { Pelo que escuto são várias desde retardo escolar, abandono e chegando até o } \\
\text { suicídio. }\end{array}$ \\
\hline $\mathrm{PB}_{17}$ & $\begin{array}{l}\text { Angústia, perda de autoestima, isolamento. Geralmente a criança ou adulto que } \\
\text { sofre de violência se sente inseguro, triste, deprimido ou aflito com mudanças de }\end{array}$ \\
\hline
\end{tabular}




\begin{tabular}{|c|l|}
\hline & humor de maneira inesperada, apresentando explosões de sentimentos. \\
\hline PB18 & $\begin{array}{l}\text { Elas apresentam baixo autoestima, ficando depressivo e como } \\
\text { consequência ocorre a evasão escolar. }\end{array}$ \\
\hline PB19 & $\begin{array}{l}\text { Isolamento interferência no ensino-aprendizagem perde a autoestima e as vezes } \\
\text { desiste da escola e depois de algum tempo retorna para se vingar. }\end{array}$ \\
\hline PB20 & Deficiência no aprendizado, isolamento, raiva e vergonha. \\
\hline
\end{tabular}

Fonte: Dados da pesquisa de campo (2021)

Percebe-se pelas falas dos professores participantes da pesquisa da Escola A e Escola B que a maioria tem a opinião de que os alunos que sofrem esse tipo de abuso na escola podem apresentar vários tipos de consequências indo desde ao isolamento e afastamento do grupo de amigos, o desinteresse de ir para a escola e a consequente evasão, como também a problemas emocionais que podem levar a ter comportamento que indique depressão e suicídio. Ou seja, nessa questão os 20 participantes tiveram respostas semelhantes e afirmaram que as salas de aula nas quais o comportamento mesmo aparecendo de maneira dispersa, de forma alterada e violenta, o índice de aprendizagem é inferior em mais de $50 \%$ da turma.

Os professores PA4, PA6, PAio da Escola A e PBi3, PAi4, PBi8, PB2o da Escola B apresentaram várias consequências, entre elas a queda no rendimento escolar, ou seja, "deficiência no aprendizado". Diante desse quadro de pouca aprendizagem é importante que o professor busque sempre oferecer situações que envolvam o diálogo entre os alunos, condicionando tais situações de maneira que sejam eficazmente educativas, visto que se trata de um profissional que tem um poder que muitas vezes nem imagina.

De acordo com Morales (2008, p. I50): um desses poderes é o de dar estrutura a situações, para que aconteçam estas ou aquelas coisas. "[...] Se lhe damos alguma tarefa ou exercício para que trabalhem em grupo durante a aula, é o que eles fazem”. Normalmente esses trabalhos em grupo (na classe ou em casa) têm um caráter acadêmico: é para que eles aprendam algo. "[...] Podemos estruturar situações para que os alunos falem entre si de coisas importantes, não diretamente acadêmicas, mas que se encaixem bem, ao menos ocasionalmente, em situações de aula normal". Não se trata de falar por falar, e sim de objetivos bem concretos.

Este tipo de atitude do professor pode abranger e favorecer além do aprendizado com qualidade, pois o aluno estará mais integrado na turma, contribuirá para que os alunos mais violentos se integrem também ao grupo.

Sobre essa questão Fante (2015, p. 157) esclarece que "certas ocorrências, consideradas como "problemas de indisciplina", ou "brincadeiras próprias da idade", podem na verdade ser fonte causadora de grande sofrimento a muitos alunos", com prejuízos emocionais impossíveis de serem reparáveis pelos traumas e consequências causadas ao seu aparelho psíquico e pelos prejuízos feitos ao desenvolvimento socioeducacional.

Dessa forma é necessário trabalhar adequadamente tanto o ato de violência isolada, a indisciplina ou o bullying direcionado a determinado aluno ou grupo, para que o processo 
de ensino-aprendizagem não seja prejudicado, visto que o profissional de educação é o responsável em identificar a diferentes formas de violência que os alunos porventura possam estar passando silenciosamente para, assim, poder ajudá-los.

Além do baixo rendimento escolar existe a evasão, timidez, solidão, constrangimento e até mesmo suicídio como apresentado pelos professores PAI, PA8 da Escola A e PBı2, PBı́6 da Escola B. A depressão é um termo usado para designar os sentimentos. É a alteração afetiva mais estudada e falada na atualidade. Considerada como transtorno de humor, conduz o indivíduo a modificar as percepções de si mesmo, alterando a visão de seus problemas classificando-os como grandes catástrofes.

É preocupante no ambiente escolar verificar comportamento entre alunos que possam prejudicar o outro nesta proporção visto que a depressão é tratada como doença da sociedade moderna, e tem características que podem traduzir uma patologia grave ou ser apenas mais um sintoma do sujeito diante de uma situação real de vida, ou seja, suas características podem determinar uma melancolia em si ou ser apenas um sintoma constituinte de outra patologia (RUFINO, et al, 2018).

$\mathrm{Na}$ escola o desejo de todos é de ter um sentimento de pertencer àquele ambiente, $\mathrm{e}$ como sentir se tem alguém lhe impedindo através de comportamentos agressivos $\mathrm{e}$ discriminatórios? Em consequência surge o sofrimento que se manifesta nas diversas condutas do cotidiano.

Todo esse sofrimento mexe com o emocional do aluno como se posicionaram os professores $\mathrm{PA}_{2}, \mathrm{PA}_{3}$ da Escola $\mathrm{A}_{\text {e }} \mathrm{PB}_{17}$ da Escola $\mathrm{B}$ ao sentirem angustia e isolamento e sentem a falta de efetividade no ambiente escolar, e dificuldade de se incluir nas atividades desenvolvidas em sala como apresentado por PA9 da Escola $\mathrm{A}$ e $\mathrm{PB}_{4}$ da Escola B de que o aluno se "sente inferior aos outros colegas". Percebe-se neste contexto uma alteração no afetivo da pessoa, para Ballone (2020) a afetividade é o estado de ânimo ou humor que traduz os sentimentos e as emoções determinando as atitudes gerais de uma pessoa diante de qualquer experiência vivencial. Para o autor a alteração mais comum encontrada na literatura a respeito dos transtornos de humor é a depressão, e que também foi o posicionamento apresentado pelos professores.

Como também que os comportamentos de violência e indisciplina dependendo do seu grau podem trazer sequelas para toda a vida do aluno, como posicionado pelo professor PAs da Escola A. É preciso está atento ao comportamento dos alunos tanto da vítima como do agressor para que situações como essa não aconteça no âmbito escolar. Da mesma forma é necessário que a escola reflita o sobre o seu papel de forma a projetar o futuro de seus alunos, e com situações de violência a vítima com certeza não terá um futuro, pois as sequelas quase sempre são para a vida toda. E considerar as palavras de Alarcão (2010, p. 25) quando afirma que uma escola reflexiva pensa no presente "para se projetar no futuro. Não ignorando os problemas atuais", como no caso de violência e indisciplina que são frequentes nas duas escolas estudadas e em muitas das escolas públicas brasileiras.

Diante dos problemas apresentados e do baixo rendimento escolar apresentado no Quadro 2 pelos participantes da pesquisa da Escola A e Escola B, buscou-se saber dos 
professores que maneira o índice de violência poderá ser reduzido ou erradicado das escolas no que diz respeito às ações ou políticas públicas destinadas para essa finalidade.

Todos os profissionais participantes do estudo da Escola A e Escola B são a favor de que haja um trabalho de reformulação nos programas de capacitações em Rede e que o poder público através de suas Secretarias de Educação (Federal, Estadual e Municipal) desenvolvam programas de valorização dos docentes e discentes com atividades culturais e dinâmicas que valorizem o potencial de cada um desses segmentos, bem como, momentos significativos de descontração, lazer e encontros coletivos, também com a participação da família.

É notório que a problemática que envolve a violência escolar faz parte de um contexto social e cultural que está inserido em diversos fatores da realidade brasileira e por essa razão, os municípios, independente de sua extensão e número populacional estão afetados pelo fenômeno negativo que tanto preocupa a comunidade interna e externa, familiares e demais segmentos no entorno da escola e de sua função de espaço que transforme, constrói e enriquece a formação e o exercício da cidadania e dos indivíduos enquanto sujeitos construtores e transformadores de sua própria cultura.

Dessa forma, observou-se que na Rede Pública de Ensino de Caruaru, em especial a Municipal, o diálogo entre os docentes, equipe técnico-pedagógica, equipe gestora e das atividades administrativas permitem que se estabeleça um desejo coletivo como um pedido de socorro urgente de políticas públicas com enfoque de proposta em políticas sociais e/ou educacionais, visto que ambas levam em conta as relações com a economia por se entender que são por meio da educação que se fundamentam as pessoas para a participação no setor produtivo, no trabalho, na criação de meios de sobrevivência.

Trabalhar com politicas públicas e propostas em políticas sociais é essencial para que haja a integração da escola com a família e a comunidade; promover e estimular ações pedagógicas; valorizar o diálogo; necessidade de práticas educativas para favorecer a prevenção e diminuição da violência; trata-se de uma contribuição do estado e sociedade.

\section{conclusões}

A violência e a indisciplina na escola é um tema que requer um conjunto de medidas, de ações integradas e de iniciativas articuladas para que possa ser reduzido este

tipo de ato, percebe-se, no entanto que não há soluções mágicas, mas é possível avançar muito na prevenção desses eventos e na educação para a convivência. Esta expressão de comportamento envolve uma multiplicidade de práticas, que muitas vezes se apresentam junta, entrelaçadas, mas que a escola deve prevenir os vários tipos de categorias que as caracterizam.

Foi verificado que os atos de indisciplinas que acontecem no interior das escolas estudadas vistas como violência escolar, têm como ocorrências mais comuns os xingamentos, embora haja também ameaças, discriminações e até roubos, e todos esses acontecimentos deixa danos físicos e psicológicos. Dessa forma é preciso construir 
diagnósticos bem elaborados com participação ampla, como um primeiro passo, seguida de ações adequadas para cada problema.

Em relação à interferência que esse tipo de comportamento violento e indisciplinar acarretam no processo de aprendizagem, constatou-se que um ambiente escolar assim torna-se pouco atrativo e inapropriado às aulas, o que acentua as faltas dos alunos e interfere na qualidade do ensino.

Tais acontecimentos trazem consequências drásticas para os alunos que sofrem com a repetência ou até mesmo com a exclusão da escola, tanto o agredido como o agressor são prejudicados em seu desenvolvimento escolar. O que exige que sejam realizadas mudanças de comportamentos com comprometimentos e ações por parte de todos que fazem parte do ambiente escolar com a realização de trabalhos para promover a superação dessas dificuldades, através de encontros, reuniões e palestras com os pais e alunos, como bem apresentado pelos professores como estratégia para eliminar esses tipos de comportamentos.

De forma geral, pode-se afirmar que os desafios enfrentados pelos professores para o enfrentamento da indisciplina e violência na Escola Municipal Caic Dr. Amaro Lyra e Silva e da Escola Municipal Cesarina Moura Vieira Costa são diversos e por isso o professor deve estar atento e preparado para lidar com a situação. Visto que são profissionais peças-chave para que os projetos de prevenção da violência escolar deem certo. A formação deve ser permanente, assim como as ações para diminuição das violências, do estresse e do esgotamento que afetam a todos. Mas principalmente o aluno, muitas vezes inocente da situação, pois a violência, com sua característica de exclusão social, agressões verbais ou físicas, ameaças, exposição indevida em mídia eletrônica, deixam sequelas tanto para vítima como para o agressor, exigindo da escola um posicionamento para que nenhum aluno, vítima ou agressor, seja prejudicado no seu desenvolvimento acadêmico e social.

\section{referências bibliográficas}

ABRAMOVAY, Mirian; RUA, Maria das Graças. Conversando sobre violência e convivência nas escolas. Rio de Janeiro: FLACSO - Brasil, OEI, MEC, 2012.

ALARCÃO, Isabel. Professores reflexivos em uma escola reflexiva. 7 ed. São Paulo: Cortez, 2010.

ARENDT, Hannah. Da Violência. Tradução Maria Claudia Drummont. Brasília: Universidade de Brasília, 2004.

BALLONE, Geraldo José. Afetividade. Rev. PsiWeb. Dez. 2020. Disponível: https://ballone.com.br/afetividade-2/. Acessado em: 05/or/2021. 
BERRINGER, Tatiana. O conceito de Estado para os estudos realistas das relações internacionais: uma análise sobre a obra A política entre as nações de Hans Morgenthau. In: USP, Plural, Revista de Ciências Sociais. V.24, n. 2, segundo semestre de 2017, p. 16-37.

ESTRELA, Maria Teresa. Relação pedagógica: disciplina e indisciplina na aula. 4 ed. Porto: Porto Editora, 2012.

ELIAS, Maria Auxiliadora. Violência escolar: caminhos para compreender e enfrentar o problema. São Paulo: Ática Educadores, 20II.

ELIAS, Norbert. “A Sociedade dos Indivíduos” (1939). Rio de Janeiro: Jorge Zahar, 1994.

FANTE, Cleo. Bullying no ambiente escolar. São Paulo: Paulinas, 2015.

FERNANDES, Daniela. Pesquisa põe Brasil em topo de ranking de violência contra professores. 2014. Disponível em: http://www.bbc.com/portuguese/noticias/ 2014/o8/140822_salasocial_eleicoes_ocde_valorizacao_professores_brasil_daniela

_rw. Acesso em: 20/o9/2020.

FINAZZI, Maria Elisa. Pupo. Breve histórico sobre a Depressão. São Paulo: Escola Paulista de Medicina, 2003.

INSTITUTO DE PESQUISA ECONOMICA APLICADA - IPEA. Atlas da Violência: Brasil registra mais de 65 mil homicídios em 2017. Publicado em 05/o6/2019. Disponível em: https://www.ipea.gov.br/portal/index.php?option=com_content\&view $=$ article $\& \mathrm{id}=34786$. Acesso em: 20/10/2020.

KAPLAN, Harold I.; SADOCK, Benjamin J.; GREBB, Jack A. Compêndio de Psiquiatria. Ciências do Comportamento e Psiquiatria Clínica. $7^{\underline{a}}$ ed. Porto Alegre: Artes Médicas 2002.

MELO, Josevaldo Araújo de. Bullying na escola: como identificá-lo, como prevení- lo, como combetê-lo. Recife: EDUP, zoro.

MORALES, Pedro. A relação professor-aluno: o que é, como se faz. $7^{\underline{a}}$ ed. São Paulo: Loola, 2008.

QUEIROZ, Phelipe Gomes. Violência Escolar: um estudo sobre a percepção dos professores de uma escola pública de sobradinho-DF. $30 \mathrm{fls}$. Faculdade UNB Planaltina. Monografia de Graduação em Licenciatura em Ciências Naturais. Brasília - Dezembro, 2015. 275p. 
RUFINO, Sueli, et al. Aspectos gerais, sintomas e diagnóstico da depressão. Revista Saúde em Foco - Edição no Io - Ano: 2018.

SANTOS, Helen. A violência presente nas relações entre alunos e professores no contexto escolar: um estudo bibliográfico. Rev. UNISUL, Ano I, fev.2017. Disponível em: http://www.uniedu.sed.sc.gov.br/wp-content/uploads/2017/o2/Artigo-Helen.pdf.

07/05/2019. Acesso em 2010/2020

TUROLlO JR, Reynado. Maioria da população diz ter medo da Polícia Militar. 2015. Disponível em: http://wwwi.folha.uol.com.br/cotidiano/2015/o7/1662655- maioria-dapopulacao-diz-ter-medo-da-policia-militar-aponta-datafolha.shtml. Acesso em 20/o9/2020. 